\title{
ANALISIS PERSEDIAAN BAHAN BAKU DALAM MENUNJANG PRODUKSI PADA USAHA MARTABAK ALIM KOTA BENGKULU
}

\author{
Ida Ayu Made Er Meytha Gayatri, Wagini \\ Program Studi Manajemen Fakultas Ekonomi Universitas Dehasen Bengkulu \\ Cinta.gayatri@yahoo.com
}

\begin{abstract}
ABSTRAK
Ida Ayu Made, Wagini; Penelitian ini bertujuan untuk mengetahui persediaan bahan baku dalam menunjang proses produksi pada usaha Martabak Alim Kota Bengkulu. Metode analisis yang digunakan adalah penentuan pembelian yang ekonomis (Economic Order Quantity), Persediaan Pengaman (Safety Stock), dan penentuan titik pemesanan kembali (Re-Order Point). Dari hasil penelitian diketahui bahwa pembelian bahan baku pada Usaha Martabak Alim Kota Bengkulu selama tahun 2017 dengan metode EOQ sebesar $433 \mathrm{~kg}$ tepung terigu khusus martabak dalam sekali pemesanan dengan frekuensi pemesanan sebanyak 4 kali dan interval 78 hari kerja. Hasil penilaian persediaan pengaman (safety stock) terhadap bahan baku tepung terigu yang dilakukan pada usaha Martabak Alim Kota Bengkulu yaitu sebesar 15 kg. penilaian waktu pemesanan kembali (Re-order point) bahan baku tepung terigu pada usaha Martabak Alim Kota Bengkulu yaitu sebesar $27 \mathrm{Kg}$. Hal ini dimaksudkan agar kedatangan bahan baku yang akan dipesan bertepatan dengan saat persediaan yang tinggal sebesar persediaan pengaman (safety stock)
\end{abstract}

\begin{abstract}
Ida Ayu Made, Wagini; This study aims to determine the inventory of raw materials in the production process to support the Martabak Alim Bengkulu City. The analytical method used was the determination of the purchase of the economy (Economic Order Quantity), Inventory Safety (Safety Stock), and the determination of the reorder point (Re-Order Point. The survey results revealed that the purchase of raw materials on Martabak Alim Bengkulu City during the year 2017 with the EOQ method is $433 \mathrm{~kg}$ of wheat flour special for Martabak in one booking with frequency ordering as many as 4 times and intervals of 78 working days. The assessment of safety stock (safety stock) against wheat flour made in Martabak Alim Bengkulu City in the amount of $15 \mathrm{~kg}$. appraisal ordering time again (Re -order point) wheat flour in Martabak Alim Bengkulu City in the amount of $27 \mathrm{Kg}$. This is so that the arrival of raw materials to be booked to coincide with the current live inventory for safety stock (safety stock)
\end{abstract}

Key Words: Analysis, Raw Material Inventory, Martabak Alim

\section{LATAR BELAKANG}

Setiap perusahaan yang bergerak dalam bidang industri, baik itu perusahaan besar, perusahaan menengah maupun perusahaan kecil sudah tentu mempunyai persediaan bahan baku. Persediaan bahan baku yang ada pada setiap perusahaan tentu berbeda dari segi jumlah maupun jenisnya, hal ini dimungkinkan karena setiap perusahaan mempunyai skala produksi dan hasil produksi yang berbeda.

Bahan baku merupakan salah satu faktor penentu dalam kelancaran proses produksi, sehingga setiap perusahaan harus mempunyai persediaan bahan baku yang cukup dalam menunjang kegiatan produksi perusahaan. Apabila persediaan bahan baku tersendat maka kegiatan proses produksi tentu akan terhambat. Terhambatnya proses produksi tentu akan berpengaruh pada output yang dihasilkan. Penurunan tingkat output ini tentu akan mempengaruhi tingkat penjualan yang berakibat perusahaan tidak mampu memenuhi permintaan konsumen. Hal ini akhirnya mempengaruhi laba perusahaan dan kepercayaan konsumen terhadap perusahaan.

Pada perusahaan industri persediaan bahan baku merupakan hal yang sangat penting untuk proses produksi, oleh karena itu perusahaan harus dapat menetapkan besarnya persediaan bahan baku yang optimal dan dapat menekan biaya persediaan agar proses produksi tetap berjalan lancar. Maka untuk maksud tersebut harus diperhatikan berbagai faktor yang terkait dalam pengadaan dan penyimpanan bahan baku. Penentuan dan pengelompokkan biaya-biaya yang terkait dengan pengadaan persediaan perlu mendapatkan perhatian yang khusus dari pihak manajemen dalam mengambil keputusan yang tepat.

Martabak Alim sebagai salah satu industri yang bergerak dalam bidang makanan mempunyai banyak varian rasa, tampilan yang bagus, dan rasanya yang lezat menjadikan usaha ini dikunjungi banyak pembeli. Oleh karena banyaknya peminat, maka dalam menunjang produksinya, manajemen Martabak Alim harus merencanakan proses produksi yang tepat agar usaha Martabak Alim berjalan lancar dan 
tidak ditinggalkan oleh pembeli. Dalam hal ini, persediaan bahan baku martabak Alim haruslah diperhitungkan dengan efektif dan efisien agar dapat memenuhi permintaan pembeli dan yang paling penting tidak mendatangkan resiko kerugian pada usaha ini.

Berdasarkan uraian di atas, maka peneliti tertarik mengangkat judul "Analisis Persediaan Bahan Baku dalam Menunjang Produksi pada Usaha Martabak Alim Kota Bengkulu".

\section{LANDASAN TEORI \\ Persediaan Bahan Baku}

Persediaan adalah barang yang disimpan atau digunakan atau dijual pada periode mendatang, dapat berupa bahan baku yang disimpan untuk proses, komponen yang diproses, barang dalam proses manufaktur dan barang jadi yang disimpan untuk dijual (Kusuma, 2005)

Rangkuti (2009) mendefinisikan persediaan adalah suatu aktiva yang meliputi barang-barang milik perusahaan dengan maksud untuk dijual dalam suatu periode usaha yang normal, atau persediaan barang-barang yang masih dalam pengerjaan atau proses produksi ataupun persediaan bahan baku yang menunggu penggunaannya dalam suatu proses produksi.

Menurut Riyanto (2013) besar kecilnya persediaan bahan baku yang dimiliki oleh perusahaan ditentukan oleh beberapa faktor antara lain:

1. Volume yang dibutuhkan untuk melindungi jalannya usaha dagang terhadap gangguan kehabisan persediaan yang akan menghambat jalannya produksi.

2. Volume produksi yang direncanakan, dimana volume produksi yang direncanakan itu sendiri sangat tergantung kepada volume sales yang direncanakan.

3. Besar pembelian bahan mentah setiap kali pembelian untuk mendapatkan biaya pembelian yang minimal.

4. Estimasi tentang fluktuasi harga bahan mentah yang bersangkutan diwaktu-waktu yang akan datang.

5. Harga pembelian bahan mentah

\section{Pengendalian Persediaan Bahan Baku}

Menurut Assauri (2004) syarat-syarat pengendalian persediaan bahan baku sebagai berikut :

1. Tempat yang cukup luas dan teratur dengan pengaturan bahan atau barang dapat dan diindentifikasikan bahan yang tertentu.

2. Pengawasan mutlak atas pengeluaran barang

3. Pencatatan yang cukup teliti yang menunjukkan jumlah yang dipesan, yang dibagikan dan yang tersedia di dalam Toko

4. Pemeriksaan barang ada dalam persediaan secara langsung.

5. Perencaan untuk menggantikan barang-barang yang telah dikeluarkan, barang-barang yang terlalu lama di dalam toko, dan barang yang telah kadarluasa.

6. Pengecekan untuk menjamin efektifnya kegiatan rutin

Pengendaalian persediaan pada divisi yang berbeda memiliki tujuan yang berbeda pula. Adapun tujuan pengendalian persediaan adalah:

1. Pemasaran ingin melayani konsumen secepat mungkin sehingga mengiginkan persediaan dalam jumlah yang banyak.

2. Produksi ingin beroperasi secara efisien, hal ini mengimplikasikan order produksi yang tinggi akan menghasilkan persediaan yang besar, disamping itu juga produk menginginkan persediaan bahan baku, setengah jadi atau komponen yang cukup sehingga proses produksi tidak terganggu karena kekurangan bahan.

3. Pembelian (purchasing), dalam rangka efisiensi, juga menginginkan persamaan produksi yang besar dalam jumlah sedikit daripada pesanan yang kecil dalam jumlah yang banyak. Pembelian juga ingin ada persediaan sebagai pembatas kenaikan harga dan kekurangan produk.

4. Keuangan (finance) menginginkan minimisasi semua bentuk investasi persediaan karena biaya investasi dan efek negatif yang terjadi pada perhitungan pengembalian aset (return of asset) perusahaan.

\section{Economic Order Quatity (EOQ)}

Economic Order Quantity (EOQ) adalah jumlah pesanan dengan biaya yang paling ekonomis. Dengan kata lain EOQ dapat diartikan jumlah pesanan dengan jumlah biaya pesanan (ordering costs) dan biaya penyimpanan (carryng costs) yang paling minimal dalam periode tertentu (Prawisantono, 2006)

Dalam teori konsep EOQ da[pat diterapkan bila naggapan-anggapan berikut ini terpenuhio (Dewi dan Kristanto, 2017): 
1. Permintaan selama satu tahun diketahui tetap dan tidak berubah

2. Harga sediaan diketahui tetap dan tidak berubah

3. Sediaan dianggap selalu tersedia sehingga dapat diperoleh setiap dibutuhkan

4. Biaya sediaan diketahui tetap dan tidak berubah

\section{Re Order Point (ROP)}

Menurut Ahyari (2002) waktu tunggu merupakan tenggang waktu yang diperlukan antara saat pemesanan bahan baku dengan datangnya bahan baku itu sendiri. Waktu tunggu ini sangat perlu untuk diperhatikan, karena hal ini sangat erat hubungannya dengan penentuan saat pemesanan kembali (ROP). Dengan diketahuinya waktu tunggu yang tepat maka perusahaan akan dapat membeli pada saat yang tepat pula, sehingga resiko penumpukkan persediaan/kekurangan persediaan dapat ditekan seminimal mungkin.

Faktor-faktor yang mempengaruhi titik pemesanan kembali (ROP) adalah:

1. Lead Time, Lead time adalah waktu yang dibutuhkan antara bahan baku dipesan hingga samapai di perusahaan. Lead time ini akan mempengrauhi besarnya bahan baku yang digunakan selama masa lead time, semakin lama lead time maka akan kembali besar bahan yang diperlukan selama masa lead time.

2. Tingkat pemakaian bahan baku rata-rata persatuan waktu tertentu.

3. Persediaan pengaman (Safety Stock), yaitu jumlah persediaan bahan minimum yang harus dimiliki oleh perusahaan untuk menjaga kemungkinan keterlambatan datangnya bahan baku.

\section{Safety Stock}

Menurut Assauri (2004), mendefinisikan tentang safety stock adalah persediaan tambahan yang diadakan untuk melindungi atau menjaga kemungkinan terjadinya kekurangan stock bahan baku (stock out).

Faktor-faktor yang mempengaruhi besar kecilnya safety stock menurut Riyanto (2001:74) yaitu :

1. Resiko kehabisan persediaan.

2. Hubungan antara biaya penyimpanan di gudang di satu pihak dengan biaya-biaya ekstra yang harus dikeluarkan sebagai akibat dari kehabisan persediaan di lain pihak.

\section{KERANGKA ANALISIS}

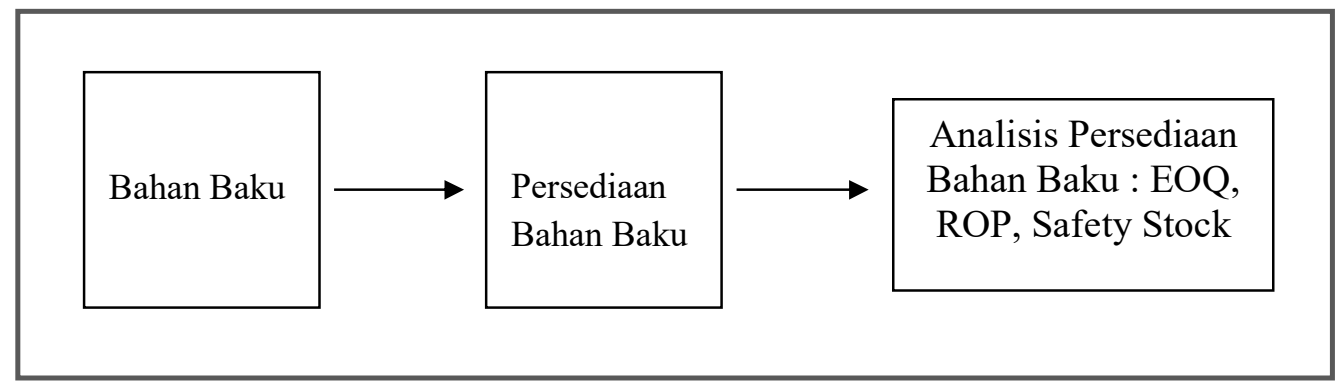

Gambar 1. Kerangka Analisis

\section{METODOLOGI}

\section{Jenis dan Metode Pengumpulan Data}

Penelitian ini termasuk jenis penelitian studi kasus yaitu penelitian yang dilakukan secara intensif, terinci dan mendalam tentang sesuatu gejala tertentu yang teliti. Adapun kasus yang dibahas mengenai persediaan bahan baku dalam menunjang proses produksi pada usaha Martabak Alim Kota Bengkulu. Pada penelitian ini menggunakan seluruh data persediaan bahan baku, produk jadi dan biaya-biaya yang ditimbulkan terhadap persediaan tersebut.

Adapun pengumpulan data pada penelitian ini menggunakan metode seperti berikut :

1. Metode wawancara tidak terstruktur, yaitu dengan cara bertanya langsung pada pimpinan usaha Martabak Alim Kota Bengkulu. Data yang ingin diketahui adalah sejarah umum perusahaan, struktur organisasi dan pembagian tugas-tugas, biaya pesan dan biaya penyimpanan, alat-alat untuk menunjang proses produksi serta lead time pemesanan bahan baku martabak. 
2. Dokumentasi yaitu pengumpulan data dengan mengumpulkan arsip-arsip dan catatan-catatan yang ada dalam laporan persediaan dan kebutuhan bahan baku yang dimiliki Martabak Alim Kota Bengkulu selama tahun 2017.

\section{Metode Analisis}

Dalam penelitian ini dilakukan melalui cara pendekatan analisis, yaitu sebagai berikut analisa kuantitatif yaitu mengadakan penganalisaan terhadap hal-hal sebagi berikut :

a. Untuk menentukan jumlah bahan baku dengan biaya minimum, maka digunakan analisa Economical Order Quantity (EOQ).

Rumus :

$\mathrm{EOQ}=\sqrt{\frac{2 \mathrm{DS}}{\mathrm{H}}}$

Dimana :

$\mathrm{D}=$ Penggunaan atau pemesanan yang diperkirakan per periode

$\mathrm{S}=$ Biaya pemesanan (ordering cost)

$\mathrm{H}=$ Biaya penyimpanan (carrying cost) per unit per tahun

(Handoko, 2012)

b. Untuk menentukan persediaan pengaman (safety stock), maka digunakan analisa statistik dengan menggunakan standar penyimpangan.

Rumus :

$\left.\sigma=\sqrt{\sum(X}-X\right){ }^{2} I n$

Dimana :

$\sigma=$ Standar penyimpangan

$X=$ Pemakaian sesungguhnya

$\mathrm{X}=$ Pemakaian rata-rata

$\mathrm{N}=$ Jumlah Data

(Nasution, 2008)

c. Untuk menentukan Re Order (ROP) digunakan formula :

Rumus :

Re Order Point $=\mathrm{U} \times \mathrm{L}+\mathrm{A}$

Dimana :

$\mathrm{U}=$ Jumlah Permintaan per hari

$\mathrm{L}=$ Kebutuhan selama waktu tunggu, atau selama lead time

$\mathrm{A}=$ Safety Stock (persediaan permintaan)

(Nasution, 2008).

\section{HASIL PENELITIAN DAN PEMBAHASAN}

Economic Order Quantity (EOQ)

Untuk menentukan jumlah biaya bahan baku tepung terigu dengan biaya minimal maka digunakan analisis Economic Order Quantity (EOQ) sebagai berikut :

$\mathrm{D}=$ Jumlah pemakaian bahan baku tepung terigu selama satu tahun yaitu $1780 \mathrm{~kg}$

$\mathrm{S}=$ Biaya pemesanan dalam 1 kali pesan yaitu Rp. 75.000,-

$\mathrm{H}=$ Biaya penyimpanan per unit per tahun yaitu Rp. $53.450 / \mathrm{kg} / \mathrm{tahun}$

Maka :

$$
\begin{aligned}
\mathrm{EOQ} & =\sqrt{\frac{2 S D}{H}} \\
& =\sqrt{\frac{2 \times 75.000 \times 1780}{1.425}}
\end{aligned}
$$




$$
\begin{aligned}
& =\sqrt{\frac{267.000 .000}{1.425}} \\
& =\sqrt{187.368,421} \\
& =432,86074 \mathrm{Kg} \approx 433 \mathrm{Kg}
\end{aligned}
$$

Dari perhitungan tersebut maka diperoleh jumlah bahan baku tepung terigu dengan biaya minimum apabila dilakukan pemesanan sebesar $433 \mathrm{~kg}$ setiap kali pesan.

Untuk mencari frekuensi pembelian selama satu periode (selama tahun 2013) perhitungannya yaitu :

$$
\begin{aligned}
\text { Frekuensi pembelian } & =\frac{D}{E O Q} \\
& =\frac{1780}{433} \\
& =4,1108545 \mathrm{kali} \approx 4 \text { kali }
\end{aligned}
$$

Untuk mencari interval atau jarak waktu dengan pemesanan yaitu sebagai berikut :

$$
\begin{gathered}
\text { Interval pemesanan }=\frac{\text { Jumlah hari kerja }}{\text { Frekuensi pembelian }} \\
=\frac{312}{4} \\
=78 \mathrm{hari}
\end{gathered}
$$

Dari hasil perhitungan tersebut dapat diketahui bahwa pembelian bahan baku tepung terigu yang paling ekonomi adalah sebesar $433 \mathrm{~kg}$ setiap kali pemesanan dengan frekuensi 4 kali dalam satu periode atau setiap 78 hari sekali, artinya dengan pemesanan sebanyak 4 kali dalam satu periode mampu menghemat biaya pemesanan dan dapat mengurangi biaya penyusutan.

\section{Persediaan Pengaman (Safety Stock)}

Penentuan persediaan pengaman dapat diketahui berdasarkan data yang diperoleh dari penelitian mengenai realisasi pemakaian bahan baku tepung terigu yang mana Martabak Alim Kota Bengkulu setiap bulannya menetapkan pemesanan bahan baku $150 \mathrm{~kg}$ tepung terigu., untuk lebih jelasnya dapat dilihat pada tabel berikut :

Tabel 1. Persiapan Perhitungan Standar Penyimpanan Bahan Baku Tepung Terigu pada Martabak Alim

\begin{tabular}{|l|c|c|c|c|}
\hline \multirow{1}{|c|}{ Bulan } & $\begin{array}{c}\text { Realisasi } \\
\text { Pemakaian } \\
(\mathrm{X})\end{array}$ & $\begin{array}{c}\text { Perkiraan } \\
\text { Pemakaian } \\
(\bar{X})\end{array}$ & $(\mathrm{X}-\bar{X})$ & $(\mathrm{X}-\bar{X})^{2}$ \\
\hline Januari & 175 & 150 & 25 & 625 \\
Fabruari & 140 & 150 & -10 & 100 \\
Maret & 120 & 150 & -30 & 900 \\
April & 150 & 150 & 0 & 0 \\
Mei & 165 & 150 & 15 & 225 \\
Juni & 135 & 150 & -15 & 225 \\
Juli & 140 & 150 & -10 & 100 \\
Agustus & 155 & 150 & -5 & 25 \\
September & 160 & 150 & 10 & 100 \\
Oktober & 150 & 150 & 0 & 0 \\
Nopember & 130 & 150 & -20 & 400 \\
Desember & 160 & 150 & 10 & 100 \\
\hline \multicolumn{4}{|c|}{$(\mathrm{X}-\bar{X})^{2}$} \\
\hline
\end{tabular}

Sumber : Martabak Alim Kota Bengkulu, 2017 
Dari data di atas dapat dihitung persediaan pengaman (safety stock) pada Martabak Alim Kota Manna sebagai berikut:

Dimana :

Standar penyimpanan $(\sigma)$

$$
\begin{aligned}
& =\frac{\sqrt{\sum(X-\bar{X})^{2}}}{n} \\
& =\frac{\sqrt{2800}}{12} \\
& =15,28 \mathrm{Kg} \approx 15 \mathrm{Kg}
\end{aligned}
$$

Jadi, persediaan pengaman (safety stock) bahan baku tepung terigu pada usaha Martabak Alim Kota Bengkulu adalah sebesar $15 \mathrm{~kg}$ artinya pada saat persediaan bahan baku tepung terigu tersisa sebesar $15 \mathrm{~kg}$, pemesanan bahan baku tepung terigu diharapkan dapat segera datang agar proses produksi martabak pada Martabak Alim Kota Bengkulu tidak terhambat.

\section{Titik Pemesanan Kembali (ROP)}

Dalam mengetahui efisiensi terhadap berapa kali pemesanan yang dilakukan dalam 1 tahun sehingga dapat mengendalikan biaya pemesanan dan biaya simpan yang dikeluarkan maka terlebih dahulu ditentukan kapan perusahaan melakukan pemesanan kembali atau re-order point. Adapun perhitungan menentukan titik pemesanan kembali Martabak Alim Kota Bengkulu sebagai berikut :

Diketahui :

$$
\begin{aligned}
& \mathrm{U}=\text { jumlah rata-rata permintaan bahan baku per hari } \\
& =\frac{1800}{312} \\
& =5,76923077 \approx 5,77 \\
& \mathrm{~L}=\text { Waktu tunggu (lead time) }=2 \text { hari } \\
& \mathrm{A}=\text { Persediaan pengaman (safety stock) }=15 \mathrm{~kg} \\
& \text { Maka : } \\
& \mathrm{ROP}=\mathrm{U} \times \mathrm{L}+\mathrm{A} \\
& =5,77 \times 2+15 \\
& =26,54 \mathrm{~kg} \approx 27 \mathrm{Kg}
\end{aligned}
$$

Dari hasil perhitungan tersebut maka usaha Martabak Alim Kota Bengkulu mengadakan pemesanan kembali bahan baku tepung terigu apabila bahan baku berada pada jumlah $27 \mathrm{~kg}$. Hal ini dimaksudkan agar kedatangan bahan baku yang akan dipesan bertepatan dengan saat persediaan yang tinggal sebesar persediaan pengaman (safety stock).

Hubungan antara Economic Order Quantity, safety stock, re-order point dan lead time setelah perhitungan pada usaha Martabak Alim Kota Bengkulu dilihat pada gambar berikut :

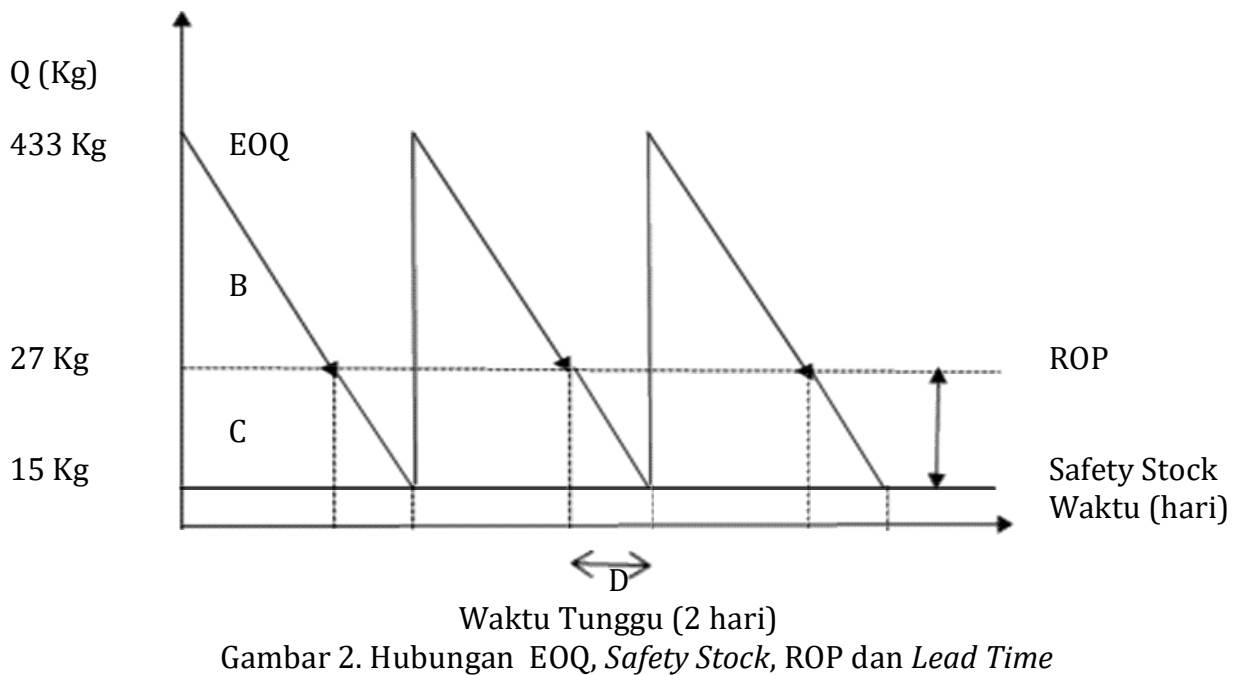


Keterangan :

A = Jumlah pembelian yang ekonomis (Economic Order Quantity sebesar $433 \mathrm{~kg}$ )

$\mathrm{B}=$ Titik pemesanan kembali (Re-order point) sebesar $27 \mathrm{Kg}$

$\mathrm{C}=$ Persediaan/Safety Stock sebesar $15 \mathrm{Kg}$

$\mathrm{D}=$ Waktu tunggu/Lead Time selama 2 hari

\section{KESIMPULAN}

1. Pada analisa EOQ maka diketahui jumlah pemesanan yang paling ekonomis pada usaha Martabak Alim Kota Bengkulu selama tahun 2017 yaitu sebesar 433 kg tepung terigu khusus martabak dalam sekali pemesanan dengan frekuensi pemesanan sebanyak 4 kali dan interval 78 hari kerja.

2. Berdasarkan penilaian persediaan pengaman (safety stock) terhadap bahan baku tepung terigu yang dilakukan pada usaha Martabak Alim Kota Bengkulu yaitu sebesar $15 \mathrm{~kg}$.

3. Berdasarkan penilaian waktu pemesanan kembali (Re-order point) bahan baku tepung terigu pada usaha Martabak Alim Kota Bengkulu yaitu sebesar $27 \mathrm{Kg}$. Hal ini dimaksudkan agar kedatangan bahan baku yang akan dipesan bertepatan dengan saat persediaan yang tinggal sebesar persediaan pengaman (safety stock).

\section{SARAN}

1. Sebaiknya dapat menerapkan konsep pembelian paling ekonomis (EOQ), persediaan pengaman (safety stock) dan titik pemesanan kembali (Re-Order Point) karena dapat memberikan keuntungan bagi pelaku usaha, dalam penelitian ini konsep tersebut membuat penggunaan bahan baku akan lebih efektif dan efisien.

2. Menerapkan dan menjaga standar kualitas martabak yang diberikan oleh pemilik waralaba

\section{DAFTAR PUSTAKA}

Agus, Ahyari 2002. Manajemen Produksi, Perencanaan, dan Pengendalian. Buku I. Edisi Revisi. Yogyakarta: BPFE

Assauri, Sofyan. 2004. Akuntansi Biaya dan Akuntansi Manajemen. Edisi Pertama. Yogyakarta: BPFE

Assauri, Sofyan. 2004. Manajemen Produksi dan Operasi. Yogyakarta: BPFE UGM

Dewi, Sofia Prima dan Septian Bayu Kristanto. 2017. Akuntansi Biaya. Bogor: In Media.

Handoko, T. Hani. 2012. Dasar-Dasar Manajemen Produksi dan Operasi. Yogyakarta: BPFE

Nasution, Arman Hakim dan Yudha Prasetyawan 2008. Perencanaan dan Pengendalian Produksi, Yogyakarta: Graha Ilmu

Rangkuti, Freddy. 2009. Analisis SWOT Teknik Membedah Kasus Bisnis. Jakarta: PT. Gramedia Pustaka Utama

Riyanto, Bambang. 2013. Dasar-Dasar Pembelanjaan Perusahaan. Edisi Keempat. Cetakan Ketujuh. Yogyakarta: BPFE

Prawirosentono, Suyadi. 2006. Manajemen Operasi (Operations Manajemen Analisis dan Studi Kasus. Jakarta: Bumi Aksara 